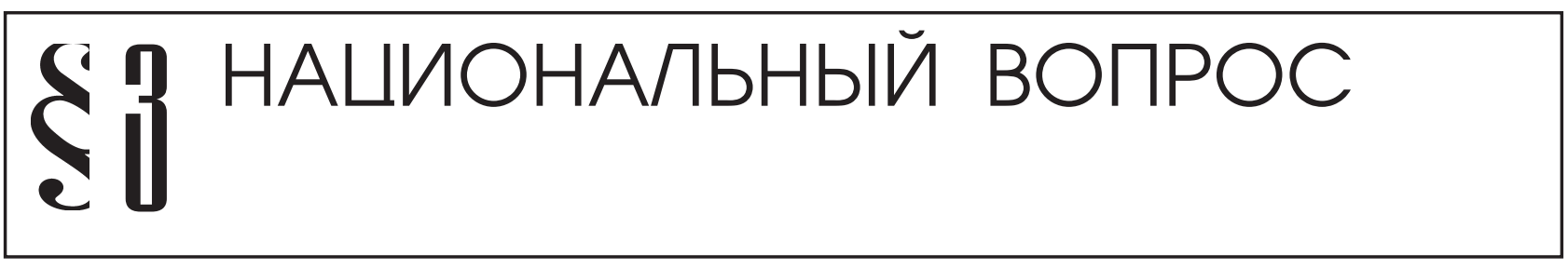

Н.П. Гриценко

\title{
РЕГИОНАЛЬНЫЕ ПОЛИТИЧЕСКИЕ ЭЛИТЫ И ПРОБЛЕМЫ ИДЕНТИЧНОСТИ В КОНТЕКСТЕ ЭТНОПОЛИТИЧЕСКИХ КОНФЛИКТОВ НА ЮГЕ РОССИИ
}

\begin{abstract}
Аннотация: В статье рассматривается роль российских региональных политических элит в формировании идентичности населения субъектов Российской Федераиии. Отмечается, что конфликтная, негативная идентичность в этнокультурном контексте способствует усугублению существующих политических конфликтов. Аргументируется необходимость формирования единой гражданской идентичности как важного условия урегулирования этнополитических конфликтов и модернизации регионов Юга России.
\end{abstract}

Ключевые слова: региональные политические элиты, идентичность, этнополитические конфликты, Юг России.

$\Gamma$ Ірупповая идентичность является значимым фактором общественно-политической жизни любого региона. Чувство принадлежности к той или иной территориальной общности или социальной группе объединяет жителей на основе единой системы ценностей, способствует устранению социальных и этнических противоречий, формирует позитивную известность территории. Идентичность является мощным политическим ресурсом региональной элиты, прежде всего связанным с поддержкой ведущих должностных лиц со стороны населения [см.: 1]. Чувство регионального сообщества сплачивает население вокруг существующей власти, которая ассоциируется с привлекательными для населения символами и образами региона, а также желаемыми социально-экономическими результатами его развития, превращает первых лиц региона в своеобразных защитников региональных интересов.

Возникновение и развитие политической идентичности является во многом результатом деятельности политических акторов, которые пытаются использовать данный феномен в своих интересах. Аналогом такого инструментального механизма формирования политической идентичности может служить механизм «изобретения традиции», описанный исследователями национализма [2, с. 92]. Таким образом, стратегии, используемые политическими акторами, ведут к тому, что существующие в обществе идентичности «транслируются» в политическую повестку дня, тем самым становясь политически значимыми. «Трансляторами» идентичностей в конкретных территориях на стадии их возникновения служат региональные элиты. От выбранных ими стратегий политической мобилизации идентичности и успеха их реализации, в конечном итоге, зависит то, в какой мере и как долго данные явления будут иметь политическое значение. Поэтому политические элиты в субъектах федерации являются наиболее значимыми акторами формирования региональных идентичностей.

По мнению В.А. Ачкасова, сохранение и устойчивость региональной идентичности в России можно объяснить с помощью концепции «внутреннего колониализма» М. Хечтера. Последний понимает его как «существование, присущее той или иной культуpe, иерархии разделения труда, которая способствует формированию реактивных групп» [цит. по: 3], поэтому «внутренний колониализм» представляет собой форму эксплуатации центром своей периферии. Пространственно неравномерные волны индустриализации в эпоху модерна усиливали маргинальность многих периферийных (провинциальных) территорий и, в конечном итоге, способствовали региональной стратификации и пространственно-территориальной иерархизации общества. Данный фактор способствует сохранению этнической и региональной идентичности на определенных территориях (иногда в латентной форме), несмотря на все попытки центра унифицировать культурные ценности. 


\section{Политика и общество 1 (97) • 2013}

Изменения в организации пространства (страны или региона) имеют следствием изменение коллективных представлений о нем, что неизбежно ведет к нарушению идентичности, созданию ее новых вариантов, возвращению к традиционным формам или даже к «потере» идентичности. Возрождение старых и формирование новых региональных мифов и идеологий отражает процесс актуализации региональной самоидентификации граждан в условиях кризиса российской идентичности и представляет собой защитную реакцию на весьма неблагоприятные изменения окружающей социально-политической среды, с которыми им пришлось столкнуться в 1990-е годы. Этим обстоятельством активно пользуются российские региональные политические элиты, которые являются главными «агентами» культивирования групповых идентичностей на уровне отдельных регионов. Как и в процессе создания национального государства, региональные деятели конструируют некую пространственно-временную идентичность в соответствии со своими интересами. Однако в отличие от процесса национального строительства, идентификационные символы должны быть изначально максимально доступны пониманию и восприятию большинства, населяющего тот или иной регион.

В данном контексте следует отметить, что этническая идентичность - результат эмоциональнокогнитивного процесса осознания этнической принадлежности, отождествление индивидом себя с представителями своего этноса и обособления от других этносов, а также глубоко личностно значимое переживание своей этнической принадлежности, результат самокатегоризации, достигаемой индивидом в итоге конструирования образа окружаемого мира и своего места в нем. В свою очередь, гражданская идентичность - это осознание человеком своей причастности к сообществу граждан того или иного государства [4, с. 10]. В политическом пространстве Юга России региональные и этнические идентичности в значительной мере накладываются друг на друга. При этом бытование различных региональных и этнических идентичностей в контексте общероссийской гражданской идентичности предполагает оживление отношений государства и этнических групп, поиск эффективных форм государственно-религиозных отношений [5, с. 233-240]. Также это предполагает самоорганизацию этнических сообществ, повышенное внимание к национально-культурному самоопределению. В Российской Федерации этнические сообщества разного численного масштаба, разного статуca, разного этнокультурного самочувствия являются равноправными участниками общественных, политических отношений, т.е. равноправными участниками культурного, национального и государственного строительства. Наиболее ярко это проявляется на Юге России - многосоставном макрорегионе РФ, гражданский и социокультурный облик которого в наибольшей степени полиэтничен и поликонфессионален.

Построение гражданской нации является необходимым условием стабилизации социально-политической ситуации в конфликтных макрорегионах. Как подчеркивает С. Маркедонов, прекращение дезинтеграции страны, достижение не провозглашаемого, а реального единства правового, политического и социально-экономического пространства станут необратимыми лишь в том случае, если у всех граждан Российской Федерации выработается ощущение принадлежности к России не на основе кровного родства, а на основе историко-культурной общности [6, с. 15]. Следует подчеркнуть, что и гражданская и этническая идентичности вписываются в другие множественные социальные идентичности.

Следует упомянуть, что в этнической конфликтологии проблеме идентичности в самых различных ее модификациях уделено существенное внимание [7, с. 83]. Для этнополитической идентичности приоритетным является политико-правовой статус, в зависимости от которого она может характеризоваться как титульная, субъектообразующая, государствообразующая, диаспорная, старожильческая, мигрантская, этноконфессиональная [8, с. 11-15]. Более того, в этнополитической идентичности отдельных групп могут сочетаться синхронный и диахронный компоненты. Например, балкарцы, ингуши, карачаевцы и чеченцы одновременно осознают себя титульными и репрессированными народами, а казачество выступает защитником государствообразующего (русского) народа и в то же время определяет себя репрессированной этнической группой, отделенной от русского народа. Русские в республиках Северного Кавказа сочетают идентичность государствообразующего народа и этнического меньшинства. Диаспорная идентичность может накладываться на мигрант- 
скую (чеченцы в «русских» субъектах) или старожильческую (армяне в Ростовской области).

Но главной функцией этнополитической идентичности является конструирование идеалов и образа будущего, фиксируемых этнополитической концепцией, которая в той или иной степени разделяется подавляющим большинством членов данной этнической группы. Общее знание, общие переживания и общие цели, зафиксированные в этнополитических концепциях, связывают членов группы и служат основой для ее отличия от других этнических групп в сфере этнополитики.

Результатом воплощения этнополитических концепций является изменение конфигурации власти и реорганизация политического пространства, что можно увидеть на примере Северного Кавказа. Этот регион отличается постоянной динамикой состава политических элит и изменениями структуры политического пространства. Так, появляются новые этнические объединения, другие теряют былой авторитет, изменяется их юридический статус, заключаются долгосрочные или ситуативные союзы, создаются и упраздняются подразделения органов власти (например, институт полпредства Президента РФ; федеральное и республиканские министерства национальной политики и т.п.).

Применительно к современной ситуации в республиках Северного Кавказа следует отметить, что этническое самосознание здесь слабо связано с идеей объединения этнических групп в единую российскую нацию. В свою очередь, гражданская идентичность предполагает знание и понимание человеком того, что он принадлежит к определенной гражданской общности, и эмоциональную значимость для него такого группового членства. По мнению В.А. Тишкова, гражданская идентичность утверждается, прежде всего, с помощью обеспечения гражданского равноправия, системы воспитания и образования, государственного языка, символов и календаря, культурного и масс-медийного производства [9]. В силу этого сам феномен гражданской идентичности может служить одним из важнейших критериев гражданской социализации личности.

На современном этапе необходимо скрупулезно исследовать взаимосвязь процессов актуализации этнической идентичности и тенденции противопоставления ее идентичности государственной в сознании жителей национальных республик Северного Кавказа. Проблемная ситуация состоит в осмыслении и преодолении противоречий между про- цессами формирования этнической и гражданской идентичностей и усилиями по поддержанию межэтнической толерантности.

Существенная роль в комплексе российской гражданской идентичности принадлежит этносоциальному и этнополитическому самоопределению (самоидентификации) гражданина, которое увязывает само явление идентичности с формированием и функционированием социальных, в том числе этнических групп. В период социальных и политических трансформаций актуализируется соотнесение этнической самоидентификации и достижения этнической идентичности с историческими, политическими процессами, а также с духовно- нравственным ресурсом группы людей как граждан государства. Именно в этом потенциале усматриваются перспективы единства россиян как многонационального народа, переживающего период социальной и политической трансформации. Также этничность включается в контекст политических отношений: электоральный и выборный процесс, процесс партогенеза и формирования многопартийности. Это осуществляется, прежде всего, в тех сообществах, где политические, а следовательно, и этнополитические процессы и институты качественно и количественно меняются в сторону расширения, углубления, усложнения своих проявлений и форм.

Российская Федерация сложилась как страна с полиэтничным, многоязычным, многоконфессиональным населением. Таковым является и социально-политическое пространство Северного Кавказа, исторически сложившегося как полиэтничный регион с мозаичным и чересполосным расселением разных социальных групп, со сложившимися и вновь образованными этнодемографическими сегментами. В известном смысле полиэтничность является наиболее яркой характеристикой региона, население здесь осознает себя, в первую очередь, представителями определенных этнокультурных сообществ, а уже потом - гражданами России.

Современные российские этнополитические и этнокультурные реалии отмечены не только продуктивным межнациональным взаимодействием, межкультурным обменом, но также и акциями национализма, ксенофобии, сепаратизма, радикализма [см.: 10]. Это выводит на авансцену деятельность региональных политических элит в области этнических, национальных и федеративных отношений. 


\section{Политика и общество 1 (97) • 2013}

Специфика этнокультурных противоречий на Юге России заключается в том, что они протекают на фоне затяжного модернизационного кризиса и конфликтов гражданской и традиционалистских идентичностей. Конфликтная, негативная идентичность в этнокультурном контексте выступает как определенная структура коллективного самосознания, продуцирующая традиционалистский ярлык «наши» - «чужие» (маркируемые в качестве априорно «враждебных» и «чуждых»). В начале XXI века на Северном Кавказе произошла деэскалация вооруженных конфликтов, но этнонационализм на фоне антимодернизации и новые региональные конфликты свидетельствуют о сложной ситуации в регионе [11].

Нарастающая демодернизация и архаизация социально-политических и экономических отношений на Северном Кавказе не позволяют обеспечить устойчивое формирование гражданской идентичности и перспективное демократическое развитие [12, с. 102]. Для населения Северного Кавказа, не принадлежащего к правящим региональным элитам, в значительной степени закрыта возможность свободной конкуренции в политической и экономической сфере, что усиливает социальное неравенство, имеющее мощный конфликтогенный потенциал. Ситуация осложняется тем, что, оставаясь неразрешенными и неурегулированными, региональные этнополитические конфликты, начавшиеся как конфликты интересов, превращаются в деструктивные конфликты идентичностей и порождают новый виток насилия, вероятность разрешения которого существенно снижается.

Для эффективного урегулирования политических конфликтов на Юге России необходимо, чтобы этническая, региональная и гражданская идентичности не конкурировали между собой. При этом, как отмечает Л.М. Дробижева, позитивными, объединяющими ценностями Россия еще не обладает $[13$, с. 460$]$. Поэтому большое значение имеет формирование особого состояния коллективного сознания общества, сознания, обладающего иммунитетом к негативным информационным воздействиям (как случайным, так и направленным) и имеющего достаточный уровень социального доверия к иноэтническим группам. По словам Ю.В. Веселова, «доверие как социальный капитал означает, что в целом в обществе формируется атмосфера доверия, что дает значительные преимущества. Люди лучше (в смысле охотнее) понимают друг друга, возрастает способность кооперативных действий. Социальная эффективность совместных действий увеличивается - незнакомые люди могут безбоязненно планировать совместные действия... Но для доверия как для социального капитала важно не только создание особой атмосферы доверия между индивидами, особый интерес представляет доверие между социальными группами, доверие индивида к социальным институтам» $[14$, с. 22]. Социальное доверие может способствовать ослаблению существующей жесткой социально-экономической конкуренции между разными социальными группами. Конкуренцию должна сменить кооперация, которая без социального доверия вряд ли возможна.

Таким образом, возникновение и развитие политической идентичности является во многом результатом деятельности политических элит, которые пытаются конструировать ее в своих интеpecax. Стратегии, используемые ведущими политическими акторами, ведут к тому, что существующие в обществе идентичности «транслируются» в политическую повестку дня, тем самым становясь политически значимыми. «Трансляторами» идентичностей в конкретных территориях на стадии их возникновения служат региональные элиты. От выбранных ими стратегий политической мобилизации идентичности и успеха их реализации, в конечном итоге, зависит то, в какой мере и как долго данные явления будут иметь политическое значение.

Возрождение старых и формирование новых региональных мифов и идеологий отражает процесс актуализации региональной самоидентификации граждан в условиях кризиса российской идентичности. Результатом становится конкуренция этнической, региональной и гражданской идентичности, особенно на Юге России.

В ситуации, сложившейся на Юге России, конструктивно регулирующая ценностные противоречия гражданская идентичность должна становиться фундаментом разрешения конфликтов идентичностей, когда из адекватного объяснения феномена конфликта (включающего и человеческие факторы) выводятся не только условия, присущие конфликтогенной среде, и структурные изменения, необходимые для устранения конфликта, но, что более важно, и условия, способствующие развитию сотрудничества и социального доверия. 


\section{Библиография:}

1. Башмаков И.С. Региональная идентичность в политической жизни Краснодарского края: ход формирования посредством символической политики власти // Теория и практика общественного развития. Краснодар, 2012. №1.

2. Гельман В.Я. Политические элиты и стратегии региональной идентичности // Журнал социологии и социальной антропологии. 2003. Т. 6. №2.

3. Ачкасов В.А. Региональная идентичность в российском политическом пространстве: «калининградский казус» // Политэкс. 2005. №3.

4. Дробижева Л.М. Государственная и этническая идентичность: выбор и подвижность // Гражданская, этническая и религиозные идентичности в современной России. М.: Изд-во Ин-та социологии РАН, 2006.

5. Аствацатурова М.А. Региональное моделирование национальной стратегии и гражданской идентичности в Северо-Кавказском регионе // Северный Кавказ в национальной стратегии России. М.: Издво Ин-та этнологии и антропологии РАН, 2008.

6. Маркедонов С. Кондопога: системный кризис российской национальной политики? // Этническая ситуация и конфликты в странах СНГ и Балтии: ежегодный доклад. М.: Изд-во Ин-та этнологии и антропологии РАН, 2007.

7. Жаде 3.А. Геополитическая идентичность России в условиях глобализации. Дис. ... д-ра полит. наук. Краснодар, 2007.

8. Хоперская Л.Л. Этнополитическая идентичность как фактор реорганизации политического пространства на Северном Кавказе // Этнопанорама. 2011. №3-4.

9. Тишков В.А. Российский народ и национальная идентичность // Профиль. 2008. 23 июня.

10. Амелин В.В. Этническое многообразие и власть в российском регионе. М.: УОП ИЭА РАН, 2004.

11. Попов М.Е. Конфликты идентичностей и гражданское самосознание: региональный аспект // http://www.lihachev.ru/pic/site/files/lihcht/2012/ Dokladi/PopovME_sec3_rus_03.03.12.pdf (дата обращения: 03.12.2012).

\section{References (transliteration):}

1. Bashmakov I.S. Regional'naya identichnost' v politicheskoy zhizni Krasnodarskogo kraya: khod formirovaniya posredstvom simvolicheskoy politiki vlasti // Teoriya i praktika obshchestvennogo razvitiya. Krasnodar, 2012. №1.

2. Gel'man V.Ya. Politicheskie elity i strategii regional'noy identichnosti // Zhurnal sotsiologii i sotsial'noy antropologii. 2003. T. 6. №2.

3. Achkasov V.A. Regional'naya identichnost' v rossiyskom politicheskom prostranstve: «kaliningradskiy kazus» // Politeks. 2005. №3.

4. Drobizheva L.M. Gosudarstvennaya i etnicheskaya identichnost': vybor i podvizhnost' // Grazhdanskaya, etnicheskaya i religioznye identichnosti V sovremennoy Rossii. M.: Izd-vo In-ta sotsiologii RAN, 2006.

5. Astvatsaturova M.A. Regional'noe modelirovanie natsional'noy strategii i grazhdanskoy identichnosti v Severo-Kavkazskom regione // Severnyy Kavkaz v natsional'noy strategii Rossii. M.: Izd-vo In-ta etnologii $\mathrm{i}$ antropologii RAN, 2008.

6. Markedonov S. Kondopoga: sistemnyy krizis rossiyskoy natsional'noy politiki? // Etnicheskaya situatsiya i konflikty v stranakh SNG i Baltii: ezhegodnyy doklad. M.: Izd-vo In-ta etnologii i antropologii RAN, 2007.

7. Zhade Z.A. Geopoliticheskaya identichnost' Rossii v usloviyakh globalizatsii. Dis. ... d-ra polit. nauk. Krasnodar, 2007.

8. Khoperskaya L.L. Etnopoliticheskaya identichnost' kak faktor reorganizatsii politicheskogo prostranstva na Severnom Kavkaze // Etnopanorama. 2011. №3-4.

9. Tishkov V.A. Rossiyskiy narod i natsional'naya identichnost' // Profil'. 2008. 23 iyunya.

10. Amelin V.V. Etnicheskoe mnogoobrazie i vlast' v rossiyskom regione. M.: UOP IEA RAN, 2004.

11. Popov M.E. Konflikty identichnostey i grazhdanskoe samosoznanie: regional'nyy aspekt // http://www.lihachev.ru/pic/site/files/lihcht/2012/Dokladi/PopovME_sec3_rus_03.03.12.pdf (data obrashcheniya: 03.12.2012). 